Case Report

\title{
Fatal Stevens-Johnson syndrome induced by phenytoin: a case report
}

\author{
Ritu J. Budania ${ }^{1}$, Ganesh N. Dakhale ${ }^{1}$, Smita D. Sontakke ${ }^{1 *}$, Pavitra S. Patnaik ${ }^{2}$
}

${ }^{1}$ Department of Pharmacology, Govt. Medical College, Nagpur-440003, Maharashtra, India

${ }^{2}$ Department of Neurosurgery, Superspeciality Hospital, Govt. Medical College, Nagpur-440003, Maharashtra, India

Received: 11 October 2013

Accepted: 27 October 2013

*Correspondence to:

Dr. Smita D. Sontakke,

Email: smitaavanti@yahoo.co.in

(C) 2013 Budania RJ et al. This is an open-access article distributed under the terms of the Creative Commons Attribution Non-Commercial License, which permits unrestricted noncommercial use, distribution, and reproduction in any medium, provided the original work is properly cited.

\begin{abstract}
Toxic epidermal necrolysis (TEN) and Stevens-Johnson syndrome (SJS) are rare (one to two per 10,00,00 population per year) but life threatening adverse drug reactions. Drugs commonly implicated are anti-epileptics, anti-microbials and non-steroidal anti-inflammatory drugs (NSAIDS). Amongst anti-epileptics, carbamazepine and phenytoin are the major culprits. We report here a fatal case of SJS due to phenytoin.
\end{abstract}

Keywords: TENS (Toxic Epidermal Necrolysis Syndrome), Phenytoin, Stevens-Johnson syndrome (SJS), Lyell syndrome

\section{INTRODUCTION}

Adverse drug reactions (ADRs) have been reported to be responsible for 0.3 to 7 percent of deaths amongst hospitalized patients. ${ }^{1}$ Stevens Johnson syndrome (SJS) and Toxic Epidermal Necrolysis (TEN) are life threatening ADRs and a leading cause of mortality. Drugs at high risk of causing SJS are anti-epileptics, antimicrobials (sulfonamides, penicillins and cephalosporins) and nonsteroidal anti-inflammatory drugs (NSAIDs). Amongst anti-epileptics, carbamazepine and phenytoin are most commonly implicated. We report here a fatal case of Stevens-Johnson syndrome due to phenytoin.

\section{CASE REPORT}

A 35 year female patient, presented with chief complaints of left sided weakness of upper and lower limbs since 20 days. There was also history of vomiting, headache and low grade fever since three days. There was no other significant past history or any known drug allergy. On examination, patient general condition was fair, conscious and oriented. Vitals were stable. Power on left side was decreased; left upper limb being 4/5 and left lower limb
4/5. Patient was admitted and investigated. Patient's MRI revealed a right cerebral frontoparietal space occupying lesion (glioblastoma). Patient was started on injection phenytoin $100 \mathrm{mg}$ thrice a day for seizure prophylaxis. Patient was operated and decompression of glioblastoma was done two weeks later. Post-operative period was uneventful.

Patient started developing erythematous rash, which gradually increased and spread all over the body. Phenytoin was stopped on the same day suspecting it to be the cause and was replaced by injection sodium valproate. Injection hydrocortisone $40 \mathrm{mg}$ was started and continued for next twelve days still the severity of rash increased. The patient had erosions, bullae involving oral mucosa and erythematous maculopapular eruption, with crusts and separation of the skin. The patient was transferred from neurosurgery ward to dermatology ward being diagnosed as Stevens-Johnson syndrome. Patient was started on intravenous antibiotics like cefotaxime, metronidazole and cleaning of skin eruptions was being done. Patient's condition deteriorated with development of hematuria and general condition of the patient worsened with Glasgow coma scale being 7/15. Two days later, patient's blood 
pressure dropped to systolic $90 \mathrm{~mm} \mathrm{Hg}$, developed unconsciousness, bilateral crepitations were present with swelling all over body. The skin lesion showed evidence of secondary infection with excoriation and foul smelling serosanguinous discharge from lesions. Patient was diagnosed as SJS with hypoproteinemia with secondary infection with septicemia in septicemic shock. Patient was transferred to intensive care unit but could not be salvaged and died.

\section{DISCUSSION}

SJS and TEN are one of the most serious, debilitating and rare (one to two per 10,00,000 population per year) ADRs. ${ }^{2}$ Both are spectrum of the same condition, in SJS less than $10 \%$ of body surface area is involved and more than $30 \%$ in TEN. ${ }^{3}$ Diagnosis is based on clinical presentation such as erythematous macules, hemorrhagic erosions along with histological analysis of skin biopsy showing typical fullthickness epidermal necrolysis due to extensive keratinocyte apoptosis. Drugs are the most common cause of SJS. It is of paramount importance to identify the medication causing SJS and withdraw it immediately. All precautions should be taken to prevent recurrence from inadvertent re-challenge. The following drugs are at high risk of causing SJS: carbamazepine, lamotrigine, nevirapine, NSAIDs, phenobarbitone, phenytoin, sulphadiazine, sulfapyridine, sulfamethoxazole, sulfasalazine., Amongst anti-epileptics, phenytoin and carbamazepine have been reported to be the most common cause. ${ }^{5}$ Hence, before prescribing these medicines, detailed history of any past drug allergy, family history of drug allergy or death in the family due to a drug should be thoroughly investigated. Varying incidences of SJS $(13.37 \%$ and $3.33 \%)$ with phenytoin have been reported by various authors. ${ }^{4,6}$

Lobao B et al reported a similar case where a patient of meningioma was given phenytoin for seizure prophylaxis and developed TEN. Intravenous fluids, systemic steroids and infection control measures were undertaken and patient recovered. ${ }^{7}$ Schmidt D et al reported a case of epileptic patient who developed fatal TEN following reexposure to phenytoin. ${ }^{8}$ Missed diagnosis in SJS-TEN is common. If the patient has recently been exposed to a drug followed by development of fever, dusky rash, mucosal erosion; then it should arouse suspicion of SJS and TEN. The risk of SJS is highest during the first two months of treatment. ${ }^{2,9}$ This patient developed SJS on the $23^{\text {rd }}$ day after starting phenytoin. Knowledge of this possibility can help prescribers in being vigilant during this period of treatment and in causality assessment. Causality analysis using Naranjo's scale showed that phenytoin is the probable cause of the adverse reaction in this case (score=6).

Supportive management is the mainstay of treatment. It involves clinical suspicion with prompt identification and withdrawal of the culprit drug. Fluid replacement with electrolytes to maintain urine output of $50-80 \mathrm{~mL} /$ hour and albumin solution infusion is recommended. ${ }^{2,3}$ Prophylactic antibiotic use is recommended. Use of corticosteroid in management of SJS is controversial. According to some, their use can lead to delayed wound healing, increased chances of infection, masking of early signs of sepsis, gastrointestinal bleeding and increased mortality. ${ }^{10}$ If steroids are to be used it should be initiated during initial stage (within 72 hours) and rapidly tapered off. ${ }^{11}$ Early administration of high-dose immunoglobulin has been recommended. ${ }^{2}$ The mortality rate of SJS and TEN is high. Renal involvement can occur in such cases causing proteinuria, haematuria, azotemia. Bacteremia/sepsis is usually the cause of death. In this case, patient developed hematuria indicating renal involvement and cause of death was sepsis with septicemic shock.

To conclude, in order to avoid morbidity and mortality associated with SJS and TEN; it is of utmost significance to be vigilant while giving drugs known to cause SJS, early diagnosis, identification of the culprit drug, its prompt withdrawal and specialized supportive care. Since phenytoin has been reported to cause SJS and TEN, its use for seizure prophylaxis needs to be reconsidered in view of safer alternatives available.

\section{Funding: None \\ Conflict of interest: None declared \\ Ethical approval: Not required}

\section{REFERENCES}

1. Doshi MS, Patel P, Shah SP, Dikshit RK. Intensive monitoring of adverse drug reactions in hospitalized patients of two medical units at a tertiary care teaching hospital. J Pharmacol Pharmacother 2012;3:308-13.

2. Thomas H, French E. Toxic epidermal necrolysis and Stevens-Johnson Syndrome. Orphanet J of Rare Dis 2010;5:39.

3. Maja Mockenhaupt. The current understanding of Stevens-Johnson syndrome and toxic epidermal necrolysis. Expert Rev Clin Immunol 2011;7(6):80315.

4. Patel TK, Barvaliya MJ, Sharma D, Tripathi C. A systematic review of the drug induced StevensJohnson syndrome and toxic epidermal necrolysis in Indian population. Indian J Dermatol Venereol Leprol 2013;79:389-9.

5. Devi K, George S, Criton S, Suja V, Sridevi PK. Carbamazepine-the commonest cause of toxic epidermal necrolysis and Stevens-Johnson syndrome: a study of 7 years. Indian J Dermatol Venereol Leprol 2005;71(5):325-8.

6. Patel PP, Gandhi AM, Desia CK, Desia MK. An analysis of drug induced Stevens-Johnson syndrome. Indian J Med Res 2012;136:1051-3.

7. Lobao B, Martins C, Sousa M, Marques S, Pedroso E. Phenytoin-induced Lyell's syndrome. BMJ case rep 2012;70:121-2. 
8. Schmidt D, Kluge W. Fatal toxic epidermal necrolysis following reexposure to phenytoin: a case report. Epilepsia 1983,24(4):440-3.

9. Patel TK, Barvaliya MJ, Sharma D, Tripathi C. A systematic review of the drug-induced StevensJohnson syndrome and toxic epidermal necrolysis in Indian population. Indian J Dermatol Venereol Leprol 2013;79:389-98.
10. Chave TA, Mortimer NJ, Sladden MJ. Toxic epidermal necrolysis: current evidence, practical management and future directions. $\mathrm{Br} \mathrm{J}$ Dermatol 2005; 153: 241-53.

11. Bilimoria FE, Shah BJ. Drug reactions. In: Valia AR, Valia RG, eds. IADVL Textbook of Dermatology. 3rd ed. Mumbai: Bhalani Publishing House;2013:1645-6.

doi:10.5455/2319-2003.ijbcp20131237

Cite this article as: Budania RJ, Dakhale GN,

Sontakke SD, Patnaik PS. Fatal Stevens-Johnson syndrome induced by phenytoin: a case report. Int $\mathrm{J}$

Basic Clin Pharmacol 2013;2:843-5. 